\title{
Deformation Mechanisms in Metastable Austenitic TRIP/TWIP Steels under Compressive Load Studied by in situ Synchrotron Radiation Diffraction**
}

By Christiane Ullrich", Stefan Martin, Christian Schimpf, Andreas Stark, Norbert Schell and David Rafaja

[*] C. Ullrich, Dr. S. Martin, Dr. C. Schimpf, Prof. Dr. D. Rafaja

Institute of Materials Science, TU Bergakademie Freiberg, Gustav-Zeuner-Str. 5, 09599 Freiberg, Germany

*E-Mail: Christiane.Ullrich@ww.tu-freiberg.de

Dr. A. Stark, Dr. N. Schell

Institute of Materials Research, Helmholtz-Zentrum Geesthacht, Max-Planck-Str. 1, 21502 Geesthacht, Germany Structural Research on New Materials, Helmholtz-Zentrum Geesthacht Outstation at DESY, Notkestr. 85, 22607 Hamburg, Germany

[**]Acknowledgements: This work was funded by the German Research Foundation (DFG) as part of a research project within the Collaborative Research Centre SFB 799, subproject B1. We would like to thank Dr. S. Decker for providing us with samples sintered by field assisted sintering technology and Mr. R. Prang for the SEM sample preparation.

Abstract: The stress-strain behavior of austenitic steels showing the TRIP/TWIP effect can be adjusted in a broad range by the addition of suitable alloying elements. Although the underlying deformation mechanisms are reasonably understood, the existing models often fail, in particular when the density of microstructure defects is high and when individual microstructure defects and features start to interact. For a micromechanical description of the material behavior involving possible interactions between different microstructure defects in austenite (dislocations, stacking faults) and newly developed phases, a detailed in situ microstructure characterization of the material under load is needed. In this study, the in situ experiments were performed using synchrotron diffraction during uniaxial compression. The materials under study are $\mathrm{Cr}-\mathrm{Mn}-\mathrm{Ni}$ steels with different Ni contents (3, 6 and 9 wt.\%) and thus different stacking fault energies (7.5, 16.7 and $24.3 \mathrm{mJm}^{-2}$ ). The in situ measurements revealed information about the martensitic phase transformations and about the development of the defect structure of austenite. The latter was concluded from the broadening and shift of diffraction lines and interpreted in terms of the squared microstrain, which is proportional to the dislocation density, and the stacking fault probability. The changes in the phase composition and defect structure are correlated with the residual elastic lattice strain. 


\section{Introduction}

High-alloy metastable austenitic steels, which show the TRIP (Transformation Induced Plasticity) and/or TWIP (Twinning Induced Plasticity) effect, exhibit outstanding properties, especially with regard to the strength, ductility and absorption of mechanical energy during plastic deformation. ${ }^{[1-3]}$ Their deformation behavior is largely controlled by the stacking fault energy (SFE) of austenite, which depends on the chemical composition of the steel and on the deformation temperature. ${ }^{[4-10]}$ For the two main classes of metastable austenitic steels, namely high-Mn steels and stainless Cr-Ni steels, the influence of SFE on the deformation mechanisms and microstructural changes in austenite was reported in Refs. ${ }^{[11-14]}$

In austenite with a very low SFE $\left(<20 \mathrm{~mJ} \mathrm{~m}^{-2}\right)$, the dissociation of partial dislocations, the formation of stacking faults and their accumulation in deformation bands are observed. ${ }^{[6,11,12,15,16]}$ A high stacking fault density leads to a local arrangement of stacking faults in deformation bands. The regular arrangement of stacking faults resembles a hexagonal crystal structure, which is identified as $\varepsilon$-martensite by diffraction methods. ${ }^{[15-17]}$ At higher deformations, the $\alpha^{\prime}$-martensite forms - preferentially inside the deformation bands or at their intersections. ${ }^{[16-18]}$ The $\alpha^{\prime}-$ martensite causes an enhanced strain hardening of the steel, especially in early deformation states. $[12,19,20]$ Increasing SFE postpones the stacking fault formation and the formation of $\alpha^{\prime}$-martensite to higher deformation stages, as a higher amount of lattice stress is required to separate the Shockley partial dislocations. ${ }^{[11,20,21]}$

For SFE above $20 \mathrm{~mJ} \mathrm{~m}^{-2}$, the formation of $\varepsilon$-martensite is gradually replaced by twinning. The twins are also produced via dissociation of dislocations and subsequent accumulation of stacking faults ${ }^{[14,15,21-24]}$, but stacking faults in twinned austenite appear on every close-packed plane, whereas in $\varepsilon$-martensite stacking faults arrange approximately on every second close-packed plane. The "dense" stacking faults forming twins act as obstacles for the dislocation slip on sec- 
ondary slip systems and provide a nearly constant strain hardening combined with a high ductility. ${ }^{[25-27]}$ For SFE $>40 \mathrm{~mJ} \mathrm{~m}$, , the deformation is mostly accomplished through the slip of perfect dislocations, because the faulting, martensitic transformation and twinning are suppressed. ${ }^{[6,12 \text {, }}$ $13,28]$

A detailed knowledge of the SFE dependence of the microstructural evolution in metastable austenitic or duplex steels during deformation is also crucial for the development and improvement of micromechanical modelling. ${ }^{[29-33]}$ Currently, the prediction of the mechanical behavior of TWIP steels with different SFEs relies on the knowledge of the twinning and dislocation microstructures explored, e.g., using electron backscatter diffraction (EBSD). ${ }^{[33]}$ For an appropriate simulation of the mechanical behavior, transformation kinetics or texture formation of TRIP/TWIP steels, however, the complex interaction between plasticity, formation and kinetics of microstructure defects, and phase transformations must be considered. ${ }^{[31,33-35]}$ EBSD reveals microstructure features such as phase fractions, textures, grain sizes, local misorientations of grains and twinning fractions, which can serve as the base of simulations of the material's behavior. ${ }^{[29-31,35]}$ However, many microstructure defects like dislocations or stacking faults are clearly beyond the spatial resolution of this method. Furthermore, EBSD is restricted to limited analyzed areas and, because of its long acquisition time, to ex situ studies. In contrast, the synchrotron diffraction can provide statistically relevant insights into the microstructure of the samples not only in terms of the phase fractions, preferred orientations of crystallites and crystallite sizes, but it can also give information about the macroscopic and microscopic lattice strains, and stacking fault probabilities. Especially the analyses of the lattice strains are only possible because of the excellent resolution of synchrotron diffraction in the reciprocal space.

Furthermore, the synchrotron diffraction experiments are very fast. The high photon fluxes allow real in situ measurements with a high coverage of the deformation steps. A series of experiments can be carried out at the same specimen, which is necessary to observe trends systematically, 
without artefacts caused by possible differences between individual post mortem samples. ${ }^{\text {[36] }}$ Thus, in situ deformation experiments using synchrotron radiation are capable of providing a coupling between bulk mechanical behavior and microstructure evolution. ${ }^{[36-39]}$ These advantages of the in situ experiments were used to analyze fundamental deformation processes. For instance, the strain hardening behavior and the underlying dislocation structures of $\mathrm{Cu}$ single crystals were studied during in situ deformation. ${ }^{[37]}$ In another example, the lattice strain level was determined from in situ synchrotron measurements in a multiphase Ti alloy and used to model the plasticity and the load partitioning between the present phases. ${ }^{[38]}$ Previous in situ synchrotron studies performed on metastable steels were focused on the tracking of a single microstructure feature, which was typically the development of the phase composition during deformation. ${ }^{[39-43]}$ Less frequently, preferred orientation of crystallites ${ }^{[41,44]}$, residual lattice strain ${ }^{[32,43]}$, line broadening of selected austenite reflections ${ }^{[40]}$ or microstrain ${ }^{[42]}$ were investigated in addition to the strain-induced phase transformations. The effect of the stacking faults on the deformation behavior of the TRIP/TWIP steels is scarcely examined in literature. Ma et al. reported about the interplay between the stacking fault probability, phase transformation and microstrain evolution. ${ }^{[39]}$

The present study describes the relationship between uniaxial mechanical compression, overall sample deformation, phase composition, preferred orientation of crystallites, and stacking fault probability, microstrain caused by perfect dislocations and residual lattice stress in austenite as obtained from in situ synchrotron radiation diffraction experiments carried out in transmission mode. Observed irregularities in the dependence of the above microstructure characteristics on the overall deformation were correlated with the post mortem micrographs of fully deformed samples and explained by the interaction of individual microstructure defects. The dependence of the deformation behavior on the stacking fault energy is discussed.

\section{Experimental}


Three fine-grained metastable austenitic $16 \mathrm{Cr}-7 \mathrm{Mn}-\mathrm{xNi}$ steels were studied. Their composition varied in the Ni content, which amounted to 3, 6 and 9 wt.\%. The exact chemical compositions and the respective grain sizes are listed in table 1. The SFE of these steels is known from in situ XRD bending tests to be $7.5,16.7$ and $24.3 \mathrm{~mJ} \mathrm{~m}^{-2}$, respectively. ${ }^{[45,46]}$ The samples with 3 and 9 wt.\% Ni were produced by powder metallurgy using field assisted sintering technique, whereas the $16 \mathrm{Cr}-7 \mathrm{Mn}-6 \mathrm{Ni}$ sample was taken from a hot-rolled bar. The hot-rolled bar was partially recrystallized, whereas the sintered specimens (16Cr-7Mn-3Ni and $16 \mathrm{Cr}-7 \mathrm{Mn}-9 \mathrm{Ni})$ were fully recrystallized.

The in situ compression tests were done at room temperature at the beamline P07, PETRA III at the DESY synchrotron facility, which was equipped with a deformation dilatometer BÄHR DIL 850. The samples for compression tests had a cylindrical shape with a diameter of $4 \mathrm{~mm}$, thus the maximum stress achievable with the $20 \mathrm{kN}$ maximum load device was $1590 \mathrm{MPa}$. The samples were compressed stepwise with a short holding time $(5 \mathrm{~s})$, during which the individual diffraction patterns were recorded. The high-energy synchrotron radiation $(100 \mathrm{keV}, \lambda=0.1235 \AA)$ allowed to conduct the diffraction experiments in transmission geometry. The size of the primary beam was $1 \mathrm{~mm}^{2}$.

Table 1: Chemical composition (as obtained from combustion analysis (C), melt extraction (N), $X$-ray fluorescence $(\mathrm{Cr}, \mathrm{Ni})$ and $\mathrm{ICP}$ spectrometry) and grain size of the investigated steel samples.

\begin{tabular}{|c|c|c|c|c|c|c|c|c|c|}
\hline \multirow[t]{2}{*}{ steel } & \multicolumn{8}{|c|}{ chemical composition [wt.\%] } & \multirow{2}{*}{$\begin{array}{l}\text { grain size }[\mu \mathrm{m}] \\
\qquad( \pm 1.5 \mu \mathrm{m})\end{array}$} \\
\hline & $\mathbf{C r}$ & Mn & $\mathbf{N i}$ & $\mathbf{S i}$ & $\mathbf{N}$ & C & Mo & $\mathbf{F e}$ & \\
\hline $16 \mathrm{Cr}-7 \mathrm{Mn}-3 \mathrm{Ni}$ & 15.6 & 7.1 & 3.03 & 0.805 & 0.054 & 0.044 & 0.033 & bal. & 5.5 \\
\hline $16 \mathrm{Cr}-7 \mathrm{Mn}-6 \mathrm{Ni}$ & 16.2 & 7.1 & 5.9 & 1.12 & 0.011 & 0.031 & 0.06 & bal. & 4.5 \\
\hline 16Cr-7Mn-9Ni & 15.7 & 7.1 & 9.7 & 1.09 & 0.073 & 0.022 & 0.02 & bal. & 7.5 \\
\hline
\end{tabular}


The synchrotron diffraction patterns were recorded using a 2D detector (PerkinElmer). In this setup, the angle between the diffraction vector and the uniaxial load direction changes with the azimuthal angle (i.e. along the Debye rings) between a half of the diffraction angle and $90^{\circ}$. The dependence of the line positions on the azimuthal angle was used for the analysis of the elastic lattice deformation upon deformation.

The electron channeling contrast imaging (ECCI) and electron back-scatter diffraction (EBSD) on deformed samples were done post mortem in a scanning electron microscope Zeiss LEO 1530 FEGSEM at $20 \mathrm{kV}$ acceleration voltage using the HKL Channel 5 EBSD software and a Nordlys detector.

\section{Data analysis}

In order to preserve the information about the dependence of the elastic lattice deformation on the direction of the macroscopic compression, the 2D diffraction images were integrated along the Debye rings within azimuthal sections having the width of $5^{\circ}$, and analyzed using the Rietveld refinement with the software MAUD. ${ }^{[47]}$ The Rietveld analysis revealed the phase fractions of fcc austenite (space group $F m \overline{3} m$ ), hcp $\varepsilon$-martensite (SG $P 6_{3} / m m c$ ) and bcc $\alpha^{\prime}$-martensite (SG $\operatorname{Im} \overline{3} \mathrm{~m}$ ), and the preferred orientation of crystallites. The high intensity of synchrotron radiation and the excellent statistical quality of the diffraction data allow to detect phase fractions $>1 \%$. For austenite, the residual elastic lattice stress $\sigma_{33}$ in the load direction, the microstrain caused by dislocations and the stacking fault probability were determined.

The lattice stress $\sigma_{33}$ was obtained from the dependence of the line shift on the inclination of the diffraction vector from the macroscopic deformation direction. For calculation of the lattice stress, the Moment Pole Stress Model ${ }^{[48]}$ was utilized, which includes the anisotropy of the elastic constants and allows therefore the description of the anisotropic ( $h k l$-dependent) line shift due to applied stress. The elastic constants of austenite $\left(C_{11}=172 \mathrm{GPa}, C_{12}=98 \mathrm{GPa}, C_{44}=123\right.$ 
$G P a)$ were taken from Refs. ${ }^{[49]}$ and ${ }^{[50]}$. The microstrain caused by dislocations was concluded from the broadening of diffraction lines. In this contribution, it is expressed in terms of the variation of the interplanar distances, $\left\langle\varepsilon_{100}^{2}\right\rangle \equiv\left\langle\left(\Delta d_{100} / d_{100}\right)^{2}\right\rangle^{[46]}$, which is directly proportional to the square root of the dislocation density. ${ }^{[51,52]}$ The crystallographic anisotropy of the line broadening was described using the Popa model. ${ }^{[53]}$ The stacking fault probability was concluded from the anisotropy of the line shift and the line broadening according to the Warren model. ${ }^{[54]}$ Presented stacking fault probabilities and microstrains were averaged over all directions of the diffraction vector with respect to the deformation direction. Preferred orientation of crystallites during the plastic deformation was described by orientation distribution functions, which were refined using the E-WIMV method that is incorporated in the MAUD routine. For the description of the texture, a model developed by Wenk et al. ${ }^{[55]}$ assuming a fiber texture was employed. The application of a texture model is necessary for a precise analysis of the phase fractions ${ }^{[56]}$, albeit the texture results are not discussed in details in the present article.

\section{Results and discussion}

\subsection{Mechanical behavior}

The true stress-strain curves (figure 1a) that were calculated from the applied force and from the sample contraction measured by the compression dilatometer show differently pronounced strain hardening (figure 1b) in the austenitic steels with different chemical compositions. The lowest stress level and strain hardening were observed in the steel with $9 \mathrm{wt} \% \mathrm{Ni}$, higher stress level and strain hardening in the steels with less Ni and thus with lower SFE. The stress-strain curve of the steel $16 \mathrm{Cr}-7 \mathrm{Mn}-3 \mathrm{Ni}$ has a distinct sigmoidal shape indicating the formation of a high amount of bec $\alpha^{\prime}$-martensite, which also raises the strain hardening for compressions $>7 \% .{ }^{[3,6}$, ${ }^{19]}$ The steel $16 \mathrm{Cr}-7 \mathrm{Mn}-6 \mathrm{Ni}$ possesses clearly the highest yield strength, which is caused, however, by its incompletely recrystallized microstructure. 
As the experiments were conducted in force-controlled mode, the maximum technical stress was equal for all samples, but the deformations achieved at the respective stress level were different. The smallest sample deformation was observed in sample $16 \mathrm{Cr}-7 \mathrm{Mn}-3 \mathrm{Ni}$, the largest one in 16Cr-7Mn-9Ni. Such strength and hardening behavior is expected, because a lower SFE and a larger extent of martensitic transformation in steels with a lower Ni content increase the stress level and reduce the deformability. ${ }^{[1,2,11,20,57]}$ However, the mechanical behavior of sample $16 \mathrm{Cr}-7 \mathrm{Mn}-6 \mathrm{Ni}$ deviates from the anticipated one, because it exhibits the highest strength in a wide deformation range. Its hardening is comparable with the hardening of the steel $16 \mathrm{Cr}-7 \mathrm{Mn}$ $3 \mathrm{Ni}$, but it decreases continuously and shows neither a plateau nor an increase throughout the whole deformation range. The possible reasons for this behavior will be discussed in detail later, as they are also reflected in the results of in situ synchrotron diffraction experiments.

\subsection{Microstructure changes during the plastic deformation as seen by in situ synchrotron dif- fraction}

\subsubsection{Martensitic phase transformation}

Figure 2 shows exemplarily an unfolded 2D diffraction pattern, which was recorded for the sample $16 \mathrm{Cr}-7 \mathrm{Mn}-3 \mathrm{Ni}$ at $24.3 \%$ compression, together with the respective Rietveld fits. Preferred orientation of crystallites is apparent from the dependence of the diffracted intensities on the azimuthal angle. The evolution of the phase fractions under compressive load concluded from the Rietveld analysis is summarized in figure 3. The initial microstructures of all three steels were fully austenitic; the crystallites were almost randomly oriented. After the deformation, the crystallites of austenite were preferentially oriented with $\langle 110\rangle$ along the deformation direction. The textures in the $\varepsilon$ - and $\alpha^{\prime}$-martensites were $\{103\}$ and $\langle 100\rangle$ fibres, respectively. In the steels with 3 and $6 \mathrm{wt} . \% \mathrm{Ni}$, the formation of hep $\varepsilon$-martensite starts very soon after the onset of the plastic deformation. The diffraction lines from $\varepsilon$-martensite were detected already between $1 \%$ and $2 \%$ 
compression for both $\mathrm{Ni}$ contents. In the low deformation range ( $3-12 \%$ compression), a slightly higher amount of $\varepsilon$-martensite was found in sample $16 \mathrm{Cr}-7 \mathrm{Mn}-6 \mathrm{Ni}$ than in sample $16 \mathrm{Cr}$ 7Mn-3Ni. The maximum amount of $\varepsilon$-martensite (ca. 19 vol.\%) was attained at ca. $20 \%$ compression for both steels.

Higher deformations lead to a slight reduction of the $\varepsilon$-martensite fraction in both steels, because the $\varepsilon$-martensite transforms partially into bec $\alpha^{\prime}$-martensite. ${ }^{[16-18]}$ The formation of $\alpha^{\prime}$-martensite starts between $2 \%$ and $3 \%$ compression for $16 \mathrm{Cr}-7 \mathrm{Mn}-6 \mathrm{Ni}$ and at ca. $4 \%$ compression for $16 \mathrm{Cr}$ $7 \mathrm{Mn}-3 \mathrm{Ni}$. In contrast to $\varepsilon$-martensite, the amount of $\alpha^{\prime}$-martensite increases faster in the steel containing 3 wt. $\%$ Ni than in the steel with 6 wt.\% Ni. The maximum content of $\alpha^{\prime}$-martensite amounted 40 vol. $\%$ for $16 \mathrm{Cr}-7 \mathrm{Mn}-3 \mathrm{Ni}$ and 30 vol. $\%$ for $16 \mathrm{Cr}-7 \mathrm{Mn}-6 \mathrm{Ni}$ at the respective maximum compression. The transformation of $\gamma$-austenite over $\varepsilon$-martensite to $\alpha^{\prime}$-martensite is a consecutive phase transition, which keeps the amount of the intermediate phase ( $\varepsilon$-martensite) almost constant.

The $16 \mathrm{Cr}-7 \mathrm{Mn}-9 \mathrm{Ni}$ steel revealed the first $\varepsilon$-martensite peaks at $6 \%$ compression, the maximum fraction of 12 vol.\% was reached at $39 \%$ compression. In this sample, the bcc $\alpha^{\prime}$-martensite did not form in the investigated deformation range, as the high Ni content stabilizes austenite, increases its SFE and lowers the driving force for the $\left(\alpha^{\prime}\right)$ martensitic transformation. ${ }^{[1,7,12,25]}$ These results are in good agreement with the results obtained for similar steels. ${ }^{[57]}$

\subsubsection{Stacking faults and microstrains}

The effect of the Ni content on the SFE can also be seen on different stacking fault probabilities (SFP) in individual samples (figure 4). In sample $16 \mathrm{Cr}-7 \mathrm{Mn}-3 \mathrm{Ni}$, an enormous increase of SFP was observed beyond $1 \%$ compression. This means that the plastic deformation of this steel is dominated by the stacking fault formation. For $16 \mathrm{Cr}-7 \mathrm{Mn}-6 \mathrm{Ni}$, a similar trend is observed showing also an early onset of the SFP increase that is comparable with sample $16 \mathrm{Cr}-7 \mathrm{Mn}-3 \mathrm{Ni}$. The 
final values of SFP are even higher for $16 \mathrm{Cr}-7 \mathrm{Mn}-6 \mathrm{Ni}$ than for $16 \mathrm{Cr}-7 \mathrm{Mn}-3 \mathrm{Ni}$. This behavior cannot be expected from the dependence of SFE on the composition, and is probably caused again by the incompletely recrystallized initial microstructure, which provides more nucleation sites for stacking fault formation and raises the internal stress above the level that is necessary to dissociate partial dislocations. ${ }^{[45,46]}$ Additionally, already in the non-deformed state the SFP was higher in $16 \mathrm{Cr}-7 \mathrm{Mn}-6 \mathrm{Ni}$ than in $16 \mathrm{Cr}-7 \mathrm{Mn}-3 \mathrm{Ni}$.

In steel $16 \mathrm{Cr}-7 \mathrm{Mn}-9 \mathrm{Ni}$, almost no stacking faults are present prior to $3 \%$ compression. The deformation in this stage runs exclusively via dislocation slip. In favorably oriented grains, the critical stress needed for dissociation of perfect dislocations and widening of stacking faults is reached first at higher deformations ( $>3 \%$ ), after a certain amount of work hardening due to the dislocations is achieved. As the microstrain in sample $16 \mathrm{Cr}-7 \mathrm{Mn}-9 \mathrm{Ni}$ is relatively low (figure 5), these dislocations form probably dislocation structures with partially compensated strain fields. ${ }^{[51]}$ Although the plastic deformation of low-SFE alloys is dominated by stacking faults, at least initial plastic deformation by dislocation slip is generally necessary for the initiation of the stacking fault formation.

In all three alloys, the increase of the stacking fault probability correlates with the increase of the $\varepsilon$-martensite fraction. Still, the formation of stacking faults in austenite precedes the $\gamma \rightarrow \varepsilon$ transition, because the diffraction methods recognize scarce (and random) stacking faults in austenite as real stacking faults, while dense (and consequently correlated) stacking faults are interpreted as $\varepsilon$-martensite. ${ }^{[15]}$ This phenomenon indicates ordering of the stacking faults, which is typical for the $\gamma \rightarrow \varepsilon$ phase transition. The interplay between the stacking fault probability and the amount of $\varepsilon$-martensite is very well visible in sample $16 \mathrm{Cr}-7 \mathrm{Mn}-6 \mathrm{Ni}$, where the temporary reduced gain of the SFP (figure 4) at approx. $13 \%$ deformation appears together with the saturation of the $\varepsilon$-martensite volume (figure 3). New increase of SFP in sample $16 \mathrm{Cr}-7 \mathrm{Mn}-6 \mathrm{Ni}$ deformed above $15 \%$, which is accompanied by a slower decay of austenite, suggests formation of new 
stacking faults in austenite as an important deformation mechanism. In the steel $16 \mathrm{Cr}-7 \mathrm{Mn}-3 \mathrm{Ni}$, this effect of boosted SFP increase is observed at a lower deformation ( $7 \%$ compression). As the $\alpha^{\prime}$-martensite formation is enhanced in this deformation range and the amount of $\varepsilon$-martensite stays almost constant, a smaller amount of the remaining austenite has to accommodate the applied load via its plastic deformation. Afterwards, less new stacking faults are produced in the deformation range $>15 \%$. Instead, more $\alpha^{\prime}$-martensite is formed that is responsible for the rising strain hardening, cf. figure $1 \mathrm{~b}$.

The squared microstrain plotted in figure 5 is a measure of the dislocation density. ${ }^{[51,52]}$ For the steel with the lowest SFE (16Cr-7Mn-3Ni), a steep initial increase in squared microstrain up to ca. $9 \%$ compression is observed. Afterwards, the increase is lowered; the rise of microstrain is slower in the compression range between 9 and $18 \%$. Concurrently, more stacking faults are formed (figure 4) and the amount of $\alpha^{\prime}$-martensite increases (figure 3). This indicates that in this compression range, the generation of new perfect dislocations is a less important deformation mechanism than the formation of stacking faults (via dislocation splitting, cf. figure 4) and $\alpha^{\prime}-$ martensite.

In the steel $16 \mathrm{Cr}-7 \mathrm{Mn}-6 \mathrm{Ni}$, the microstrain increases almost linearly during the whole deformation process. The high initial microstrain indicates again that this sample was not completely recrystallized, as it had a high dislocation density already prior to the in situ deformation. Compared to the two other steel compositions, the initial squared microstrain was more than doubled. The high dislocation density in the starting state contributes to an early onset of the martensitic transformation that occurs at a similar deformation like in the steel $16 \mathrm{Cr}-7 \mathrm{Mn}-3 \mathrm{Ni}$ (figure 3) despite a higher SFE in the steel containing 6 wt.\% Ni. Nevertheless, the microstrain in $16 \mathrm{Cr}$ $7 \mathrm{Mn}-6 \mathrm{Ni}$ attains a clearly higher level than in sample $16 \mathrm{Cr}-7 \mathrm{Mn}-3 \mathrm{Ni}$, and shows a constant increase that indicates an enhanced dislocation slip activity throughout the compressive loading. 
The steel containing $9 \mathrm{wt} . \% \mathrm{Ni}$ possesses nearly the same initial microstrain as the steel $16 \mathrm{Cr}$ $7 \mathrm{Mn}-3 \mathrm{Ni}$. The squared microstrain in sample $16 \mathrm{Cr}-7 \mathrm{Mn}-9 \mathrm{Ni}$ also increases linearly upon deformation, but its maximum is clearly lower than in sample $16 \mathrm{Cr}-7 \mathrm{Mn}-6 \mathrm{Ni}$ despite a higher true compression. The high SFE in sample $16 \mathrm{Cr}-7 \mathrm{Mn}-9 \mathrm{Ni}$ retards the stacking fault formation and promotes the dislocation slip activity as the primary deformation mechanism. ${ }^{[12,21,22,28]} \mathrm{New}$ perfect dislocations are produced during the whole deformation process, even in the deformation range, in which the stacking faults form. When comparing the microstrain evolution in the three steels under study, it is obvious that the contribution of the dislocation slip to the plastic deformation decreases with decreasing SFE, because other deformation mechanisms such as the formation of stacking faults and phase transformation become dominant.

\subsection{Complementarity of the mechanical testing and the in situ diffraction experiments}

Another result of the in situ synchrotron diffraction experiment done under deformation was the information about the residual elastic lattice stress in austenite and about its dependence on the macroscopic deformation (figure 6a) as a complement to the stress-strain curve from figure 1. The residual elastic lattice stress was obtained from the dependence of the line positions on the azimuthal angle in the $2 \mathrm{D}$ diffraction pattern ${ }^{[58]}$ taking into account the crystallographic anisotropy of the elastic constants.

In the elastic deformation range (approx. below $0.5 \%$ compression), the mechanical stress (figure 1) and the lattice stress in austenite (figure 6a) agree quite well. After the plastic deformation starts, the mechanical stress becomes higher than the lattice stress in austenite. The difference between the total stress obtained from the mechanical experiment and the elastic lattice stress obtained from the in situ diffraction experiment increases during the compression (figure 6b). The reason for this difference is that the mechanical stress contains also the component, which is needed for the elastic and plastic deformation of other phases present in the sample, whereas the lattice stress obtained from the synchrotron diffraction comprises only the residual (elastic) stress 
in austenite. The difference between the mechanical stress and the elastic lattice stress in austenite

is related to the expected strain hardening of the samples due to the deformation-induced martensitic phase transformations. ${ }^{[6,19,20]}$ The increasing strain hardening rate of $16 \mathrm{Cr}-7 \mathrm{Mn}-3 \mathrm{Ni}$ (figure 1b) is correlated with the high formation rate of $\alpha^{\prime}$-martensite at higher deformations (> $10 \%$ ) and also manifested in the pronounced stress difference (figure $6 \mathrm{~b}$ ). The positive stress difference means that the elastic lattice strain and stress in austenite are reduced by its plastic deformation, which is connected with the formation of perfect dislocations (figure 5) and stacking faults (figure 4$)$.

The strain hardening is also demonstrated by the increase of the residual lattice stress in austenite in the plastic deformation range. This increase indicates mechanical interaction of austenite with other phases and the interaction between individual microstructure defects caused by the increasing density of microstructure defects and by the overlap of their stress fields. ${ }^{[39,42-44]}$ In the steels with lower SFE and pronounced martensitic transformation $(16 \mathrm{Cr}-7 \mathrm{Mn}-3 \mathrm{Ni}$ and $16 \mathrm{Cr}-7 \mathrm{Mn}-$ $6 \mathrm{Ni}$ ), the mechanical stress is strongly influenced by the formation of $\alpha^{\prime}$-martensite and therefore the stress difference rises with increasing amount of the martensite fraction. ${ }^{[4]}$

\subsection{Microstructure changes induced by plastic deformation as seen by microscopic methods}

The anticipated interaction of individual microstructure defects was confirmed by electron channeling contrast imaging (ECCI) and electron backscatter diffraction (EBSD) in scanning electron microscope (SEM). ECCI revealed that in sample $16 \mathrm{Cr}-7 \mathrm{Mn}-3 \mathrm{Ni}$, the deformation bands occur generally on several slip planes, where they provide nucleation sites for the $\alpha^{\prime}$-martensite formation (figure 7a). Additional nucleation sites can also be found inside the deformation bands consisting of $\varepsilon$-martensite. The remaining austenite matrix is plastically deformed mainly through the stacking fault mechanism, thus the dislocation slip and the formation of dislocation structures are less noticeable. 
The microstructure of the steel $16 \mathrm{Cr}-7 \mathrm{Mn}-6 \mathrm{Ni}$ (figure $7 \mathrm{~b}$ ) is also characterized by a high stacking fault density in austenite, and the presence of many deformation bands on several slip systems and nuclei of $\alpha^{\prime}$-martensite. Additionally, pronounced contrasts from dislocations evidence a highly partitioned microstructure and verify the high dislocation density revealed by the analysis of the diffraction line broadening (figure 5). The incompletely recrystallized initial microstructure causes a fine-scaled defect arrangement.

The ECCI image of the steel 16Cr-7Mn-9Ni (figure 7c) affirms the dominant role of the dislocation slip in the deformation of this sample. Some areas are free of typical deformation bands, while tangled dislocations and dislocation walls are visible. The EBSD measurement performed on this sample (figure 7d) revealed considerable misorientations inside of the grains, which can be interpreted as local lattice rotations caused by the presence of dislocation structures or even dislocation walls. The interaction between deformation bands and perfect dislocations results in a curvature of the deformation bands. Furthermore, the results of EBSD analysis (figure 7d) demonstrate that the deformation bands consist partly of twins and partly of $\varepsilon$-martensite. In sample $16 \mathrm{Cr}-7 \mathrm{Mn}-9 \mathrm{Ni}$, no $\alpha^{\prime}$-martensite was found using EBSD, which is also in a good agreement with the result of the phase analysis using synchrotron radiation diffraction. The proof of the presence of twins using synchrotron diffraction is difficult. Twins cause both, the broadening and asymmetry of X-ray diffraction lines ${ }^{[54]}$, but the X-ray diffraction is generally less sensitive to the presence of twins than to the presence of stacking faults and dislocations. Thus, the twins in deformed samples were detected much more easily by ECCI and EBSD in SEM.

\subsection{Dependence of the deformation mechanisms on the stacking fault energy}

The proportions between individual hardening mechanisms follow from the comparison of the stress difference (figure 6b) with the phase fractions (figure 3), stacking fault probability (figure 
4) and squared microstrain (figure 5). The steep increase of the stress difference that was observed in samples $16 \mathrm{Cr}-7 \mathrm{Mn}-3 \mathrm{Ni}$ and $16 \mathrm{Cr}-7 \mathrm{Mn}-6 \mathrm{Ni}$ at low compressions is mainly caused by the formation of stacking faults and $\varepsilon$-martensite. As $\varepsilon$-martensite originates from faulted austenite with dense packed stacking faults ${ }^{[15]}$, the formation of stacking faults and $\varepsilon$-martensite are coupled phenomena that have a similar effect on the stress-strain curve, i.e., they act as obstacles for dislocations glide particularly on the secondary slip system. ${ }^{[6,20,22,39]}$ The main contribution to the increase of the stress difference and thus to the strain hardening in sample $16 \mathrm{Cr}-7 \mathrm{Mn}-3 \mathrm{Ni}$ at the deformations above $\sim 9 \%$ stems from the formation of $\alpha^{\prime}$-martensite. This model is also applicable for sample $16 \mathrm{Cr}-7 \mathrm{Mn}-9 \mathrm{Ni}$, in which the increase of the stress difference is delayed in the same manner as the formation of the stacking faults and the $\varepsilon$-martensite.

In steel $16 \mathrm{Cr}-7 \mathrm{Mn}-9 \mathrm{Ni}$, the stacking fault probabilities are distinctly lower than in steels with lower Ni contents. As the plasticity of the steel with $9 \mathrm{wt} . \% \mathrm{Ni}$ cannot be explained solely by a high dislocation density, by the formation of isolated stacking faults or by an extensive $\varepsilon$-martensite transformation, the formation of deformation twins in the austenite must be considered. Their occurrence in this type of steel was already reported. ${ }^{[22,57]}$

\section{Conclusions}

The deformation-induced microstructure changes in metastable austenitic steels having different stacking fault energies were studied using in situ synchrotron radiation diffraction under compressive load. The formation of dislocations, stacking faults and twins, and the martensitic transformation of austenite to $\varepsilon$-martensite and $\alpha^{\prime}$-martensite were correlated with the stress-strain curves obtained from the mechanical experiments and with the residual elastic lattice deformation obtained from the diffraction experiments. In all steels under study, the plastic deformation starts with the production and slip of perfect dislocations, and proceeds with the formation 
of stacking faults and twins and with the martensitic transformation. The significance of the respective deformation mechanism depends strongly on the deformation degree and, particularly at higher deformations, on the stacking fault energy, which controls the onset of the rapid dissociation of partial dislocations and the stacking fault formation.

Especially in steels with higher stacking fault energies, some critical stress must be reached to be able to activate the partial dislocation dissociation and the stacking fault formation. The critical stress can be produced by interacting microstructure defects, in particular by interaction of perfect dislocations. With increasing Ni content and increasing stacking fault energy, the stacking fault formation and the martensitic phase transformations are retarded, the formation of $\alpha^{\prime}$-martensite is suppressed, and the importance of the dislocation slip increases. A higher initial defect density, as present in sample $16 \mathrm{Cr}-7 \mathrm{Mn}-6 \mathrm{Ni}$, brings about higher defect densities (stacking faults and dislocations) and an earlier onset of the stacking fault formation and phase transformation during deformation, mainly due to a higher level of lattice stress in austenite.

\section{References}

[1] A. Jahn, A. Kovalev, A. Weiß, S. Wolf, L. Krüger, P.R. Scheller, steel res.int. 2011, 82, 39.

[2] L. Krüger, S. Wolf, U. Martin, S. Martin, P.R. Scheller, A. Jahn, A. Weiß, $15^{\text {th }}$ International Conference on the Strength of Materials (ICSMA-15) J. Phys. 2010, 240, 1.

[3] G. Frommeyer, U. Brüx, P. Neumann, ISIJ Int. 2003, 43, 438.

[4] L. Rémy, Acta metal. 1977, 25, 173.

[5] L. Rémy, Metall. Trans. A 1977, 8A, 253.

[6] S. Martin, S. Wolf, U. Martin, L. Krüger, D. Rafaja, Metall. Mater. Trans. A 2016, A47, 49.

[7] S. Martin, O. Fabrichnaya, D. Rafaja, Mater. Lett. 2015, 159, 484.

[8] F. Lecroisey, A. Pineau, Metall. Trans. 1972, 3, 387.

[9] S. Allain, J.-P. Chateau, O. Bouaziz, S. Migot, N. Guelton, Mater. Sci. Eng. A 2004, 387$389,158$. 
[10] A. Saeed-Akbari, J. Imlau, U. Prahl, W. Bleck, Metall. Mater. Trans. A 2009, 40, 3076.

[11] J. Talonen, H. Hänninen, Acta Mater. 2007, 55, 6108.

[12] D.T. Pierce, J.A. Jiménez. J. Bentley, D. Raabe, J.E. Wittig, Acta Mater. 2015, 100, 178.

[13] L. Rémy, A. Pineau, Mater. Sci. Eng. 1977, 28, 99.

[14] A.S. Hamada, L.P. Karjalainen, R.D.K. Misra, J. Talonen, Mater. Sci. Eng. A 2013, 559, 336.

[15] S. Martin, C. Ullrich, D. Šimek, U. Martin, D. Rafaja, J. Appl. Cryst. 2011, 44, 779.

[16] S. Martin, C. Ullrich, D. Rafaja, Mater. Today: Proceedings 2015, 2S, 643.

[17] L. Bracke, L. Kestens, J. Penning, Scripta Mater. 2007, 57, 385.

[18] G.B. Olson, M. Cohen, J. Less Common Metals 1972, 28, 107.

[19] T. Narutani, Mater. Trans. JIM 1989, 30, 33.

[20] L. Bracke, G. Mertens, J. Penning, B.C. DeCooman, M. Liebeherr, N. Akdut, Metall. Mater. Trans. A 2006, 37, 307.

[21] Y. Shen, X. Li, Y. Sun, L. Wang, L. Zuo, Mater. Sci. Eng. A 2012, 552, 514.

[22] C. Ullrich, R. Eckner, L. Krüger, S. Martin, V. Klemm, D. Rafaja, Mater. Sci. Eng. A 2016, 649, 390 .

[23] L. Bracke, L. Kestens, J. Penning, Scripta Mater. 2009, 61, 220.

[24] J.-K. Kim, M.-H. Kwon, B.C. DeCooman, Acta Mater. 2017, 141, 444.

[25] L. Rémy, A. Pineau, B. Thomas, Mater. Sci. Eng. 1978, 36, 47.

[26] S. Allain, J.-P. Chateau, O. Bouaziz, Mater. Sci. Eng. A 2004, 387-389, 143.

[27] O. Bouaziz, S. Allain, C.P. Scott, P. Cugy, D. Barbier, Curr. Opin. Solid State Mater. Sci. 2011, $15,141$.

[28] S. Curtze, V.-T. Kuokkala, Acta Mater. 2010, 58, 5129.

[29] C.C. Tasan, M. Diehl, D. Yan, C. Zambaldi, P. Shanthraj, F. Roters, D. Raabe, Acta Mater. 2014, 81, 386.

[30] C.C. Tasan, M. Diehl, D. Yan, M. Bechtold, F. Roters, L. Schemmann, C. Zheng, N. Peranio, D. Ponge, M. Koyama, K. Tsuzaki, D. Raabe, Annu. Rev. Mater. Res. 2015, 45, 391

[31] S.L.Wong, M. Madivala, U, Prahl, F. Roters, D. Raabe, Acta Mater. 2016, 118, 140.

[32] E. Jimenez-Melero, N.H. van Dijk, L. Zhao, J. Sietsma, J.P. Wright, S. van der Zwaag, Mater. Sci. Eng. A 2011, 528, 6407. 
[33] B.C. De Cooman, Y. Estrin, S. K. Kim, Acta Mater. 2018, 142, 283.

[34] M. Cherkaoui, M. Berveiller, X. Lemoine, Int. J. Plast. 2000, 16, 1215.

[35] B. Petit, N. Gey, M. Cherkaoui, B. Bolle, M. Humbert, Int. J. Plast. 2007, 23, 323.

[36] H. Van Swygenhoven, S. Van Petegem, Mater. Charact. 2013, 78, 47

[37] E. Schafler, K. Simon, S. Bernstorff, P. Hanák, G. Tichy, T. Ungár, M.J. Zehetbauer, Acta Mater. 2005, 53, 315.

[38] S.L. Raghunathan, A.M. Stapleton, R.J. Dashwood, M. Jackson, D. Dye, Acta Mater. 2007, 55, 6861 .

[39] Y. Ma, W. Song, W. Bleck, Materials 2017, 10, 1129.

[40] P. Hedström, U. Lienert, J. Almer, M. Odén, Scripta Mater. 2007, 56, 213.

[41] E. Cakmak, H. Choo, K. An, Y. Ren, Acta Mater. 2012, 60, 6703.

[42] C. Gauss, I.R. Souza Filho, M.J.R. Sandim, P.A. Suzuki, A.J. Ramirez, H.R.Z. Sandim, Mater. Sci. Eng. A 2016, 651, 507.

[43] P. Hedström, L.E. Lindgren, J. Almer, U. Lienert, J. Bernier, M. Terner, M. Odén, Metall. Mater. Trans. A 2009, 40, 1039.

[44] K. Yan, D.G. Carr, M.D. Callaghan, K.-D. Liss, H. Li, Scripta Mater. 2010, 62, 246.

[45] D. Rafaja, C. Krbetschek, D. Borisova, G. Schreiber, V. Klemm, Thin Solid Films 2013, $530,105$.

[46] D. Rafaja, C. Krbetschek, C. Ullrich, S. Martin, J. Appl. Cryst. 2014, 47, 936.

[47] L. Lutterotti, S. Matthies, H.R. Wenk, IUCr Commission on Powder Diffraction Newsletter 1999, 21, 14.

[48] S. Matthies, G.W. Vinel, phys. stat. solidi 1982, 112, 111.

[49] D.T. Pierce, K. Nowag, A. Montagne, J.A. Jiménez, J.E. Wittig, R. Ghisleni, Mater. Sci. Eng. A 2013, 578, 134.

[50] H.M. Ledbetter, phys. stat. solidi A 1984, 86, 89.

[51] M. Wilkens, phys. stat. solidi A 1970, 2, 359.

[52] T. Ungár, A. Borbély, Appl. Phys. Lett. 1996, 69, 3173.

[53] N.C. Popa, J. Appl. Cryst. 1998, 31, 176.

[54] B.E. Warren, X-Ray Diffraction New York: Dover, USA 1969. 
[55] H.R. Wenk, S. Grigull, J. Appl. Cryst. 2003, 36, 1040.

[56] A. Creuziger, C.A. Calhoun, W.A. Poling, T. Gnäupel-Herold, J. Appl. Cryst. 2018, 51, 720 .

[57] A. Vinogradov, A. Lazarev, M. Linderov, A. Weidner, H. Biermann, Acta mater. 2013, $61,2434$.

[58] S. Merkel, H.P. Liermann, L. Miyagi, H.R. Wenk, Acta mater. 2013, 61, 5144. 


\section{Figures}

a)

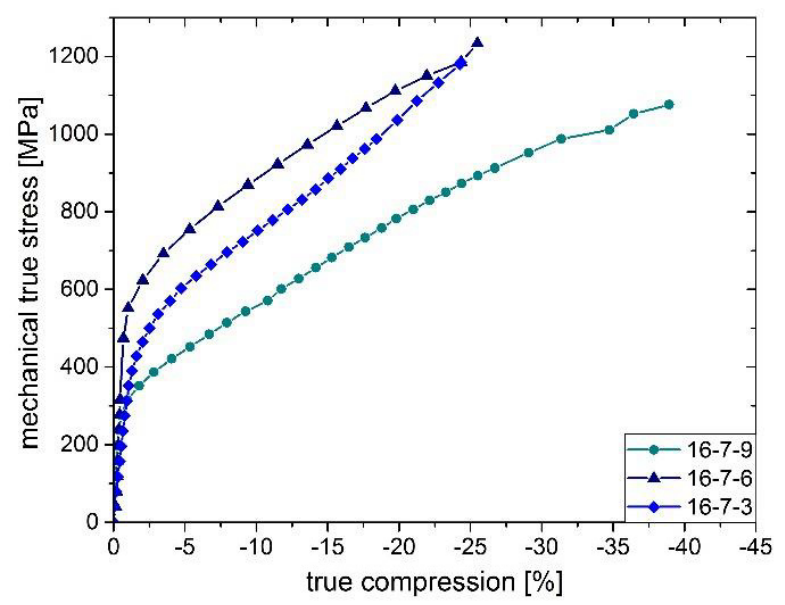

b)

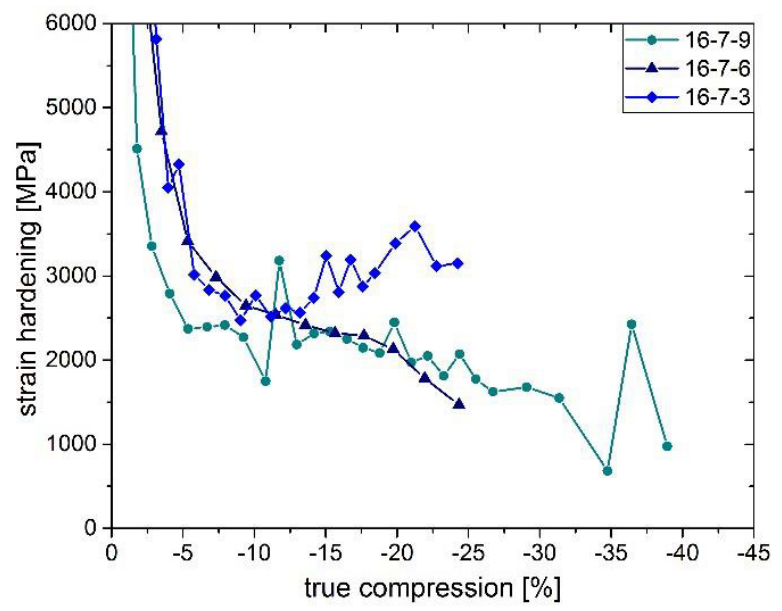

Figure 1. (a) True stress-true strain curves measured for the metastable austenitic steel samples under study. (b) Strain hardening curves calculated from the true stress-true strain curves. Due to the low number of measurement data points, the scatter is large ( $600 \mathrm{MPa}$ ), but the trends are well visible.

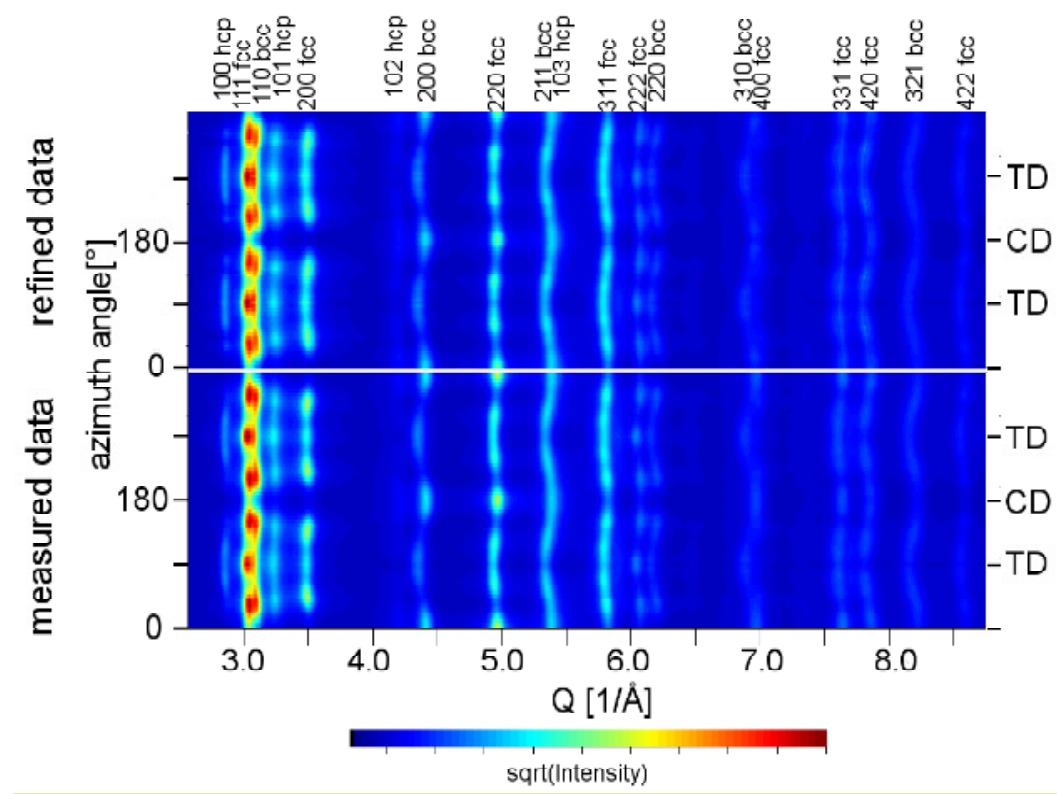

Figure 2. Measured and refined diffraction patterns of sample $16 \mathrm{Cr}-7 \mathrm{Mn}-3 \mathrm{Ni}$ after $24.3 \%$ compression. $Q$ is the magnitude of the diffraction vector. Azimuth angle corresponds roughly to the angle between the deformation direction and the direction of the diffraction vector. The azimuth angles of $90^{\circ}$ and $270^{\circ}$ correspond to the transverse direction (TD), $0^{\circ}$ and $180^{\circ}$ are nearly along the compression direction (CD). The most prominent peaks are labelled at the top. 


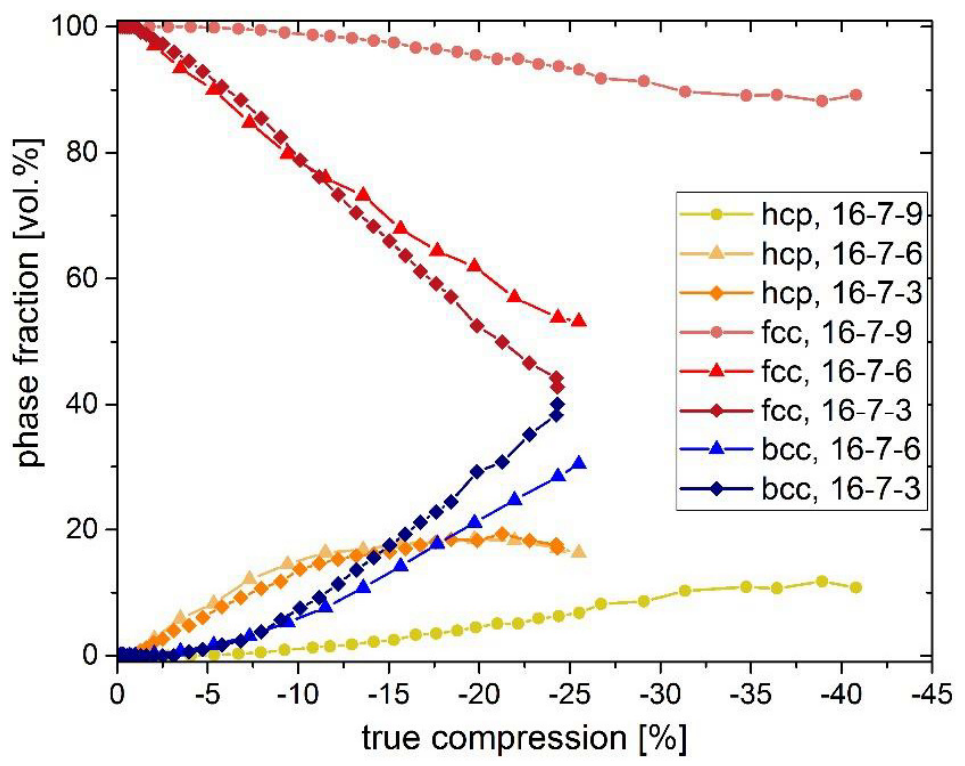

Figure 3. Evolution of the phase fractions as obtained from the Rietveld refinement.

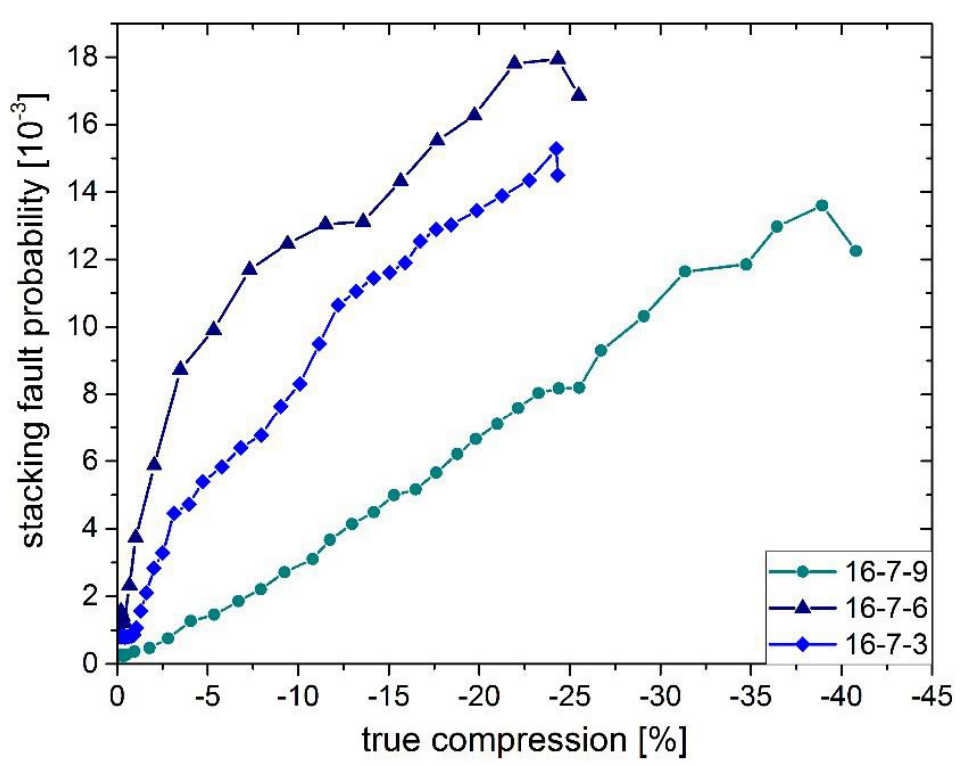

Figure 4. Probability of isolated intrinsic stacking faults in austenite as obtained from anisotropic line shift and anisotropic line broadening by using the Warren model [54]. 


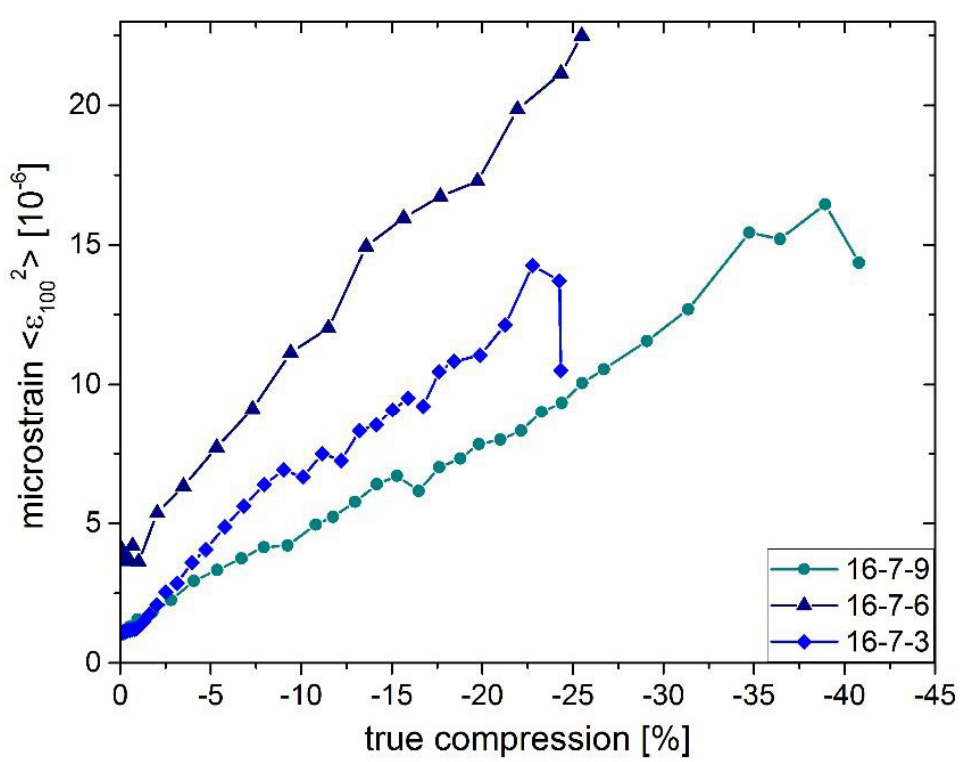

Figure 5. Dependence of the squared microstrain $\left\langle\varepsilon_{100}^{2}\right\rangle$ in austenite on the true compression of the respective steel.

a)

b)

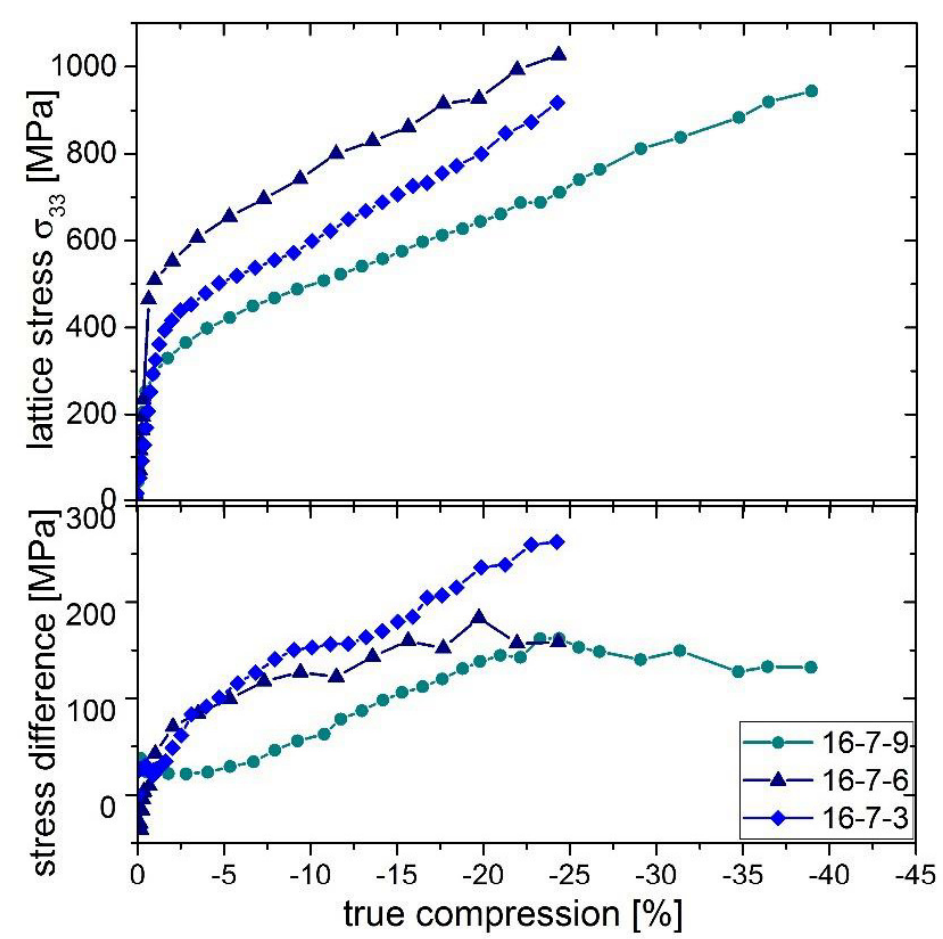

Figure 6. (a) Elastic lattice stress $\sigma_{33}$ in austenite (stress in the compression direction) obtained from the shift of the diffraction lines. (b) Difference between the mechanical true stress from figure 1 and the elastic lattice stress. 


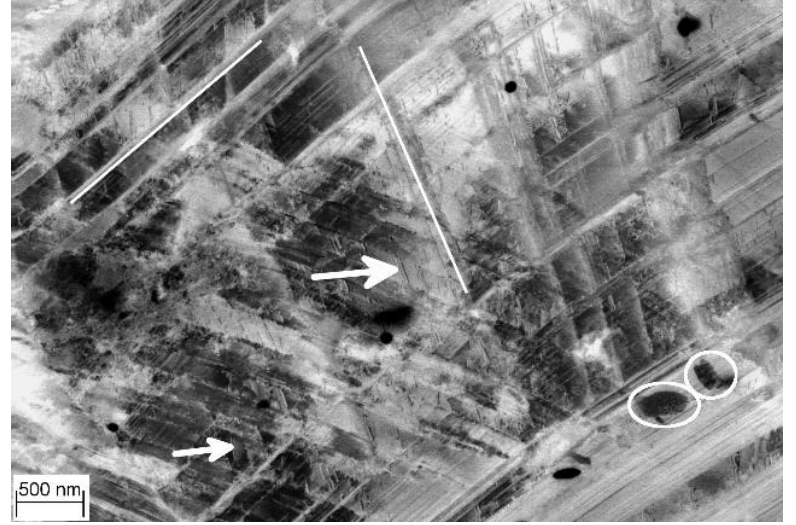

a) $16 \mathrm{Cr}-7 \mathrm{Mn}-3 \mathrm{Ni}$

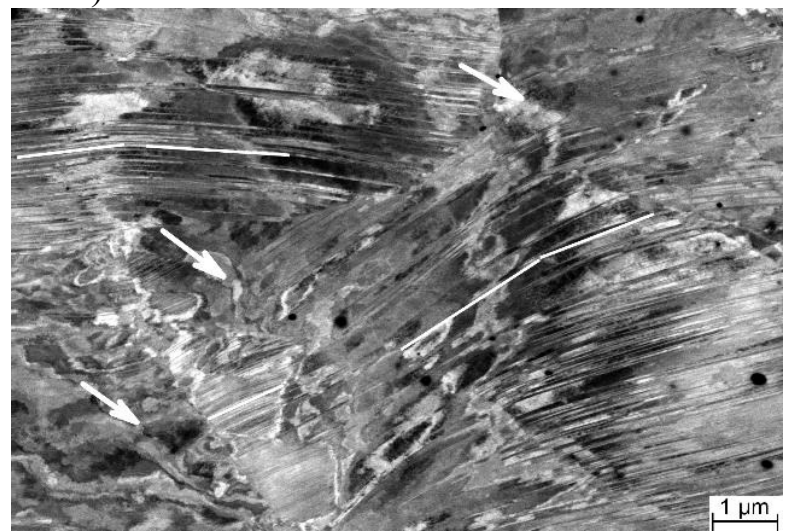

c) $16 \mathrm{Cr}-7 \mathrm{Mn}-9 \mathrm{Ni}$

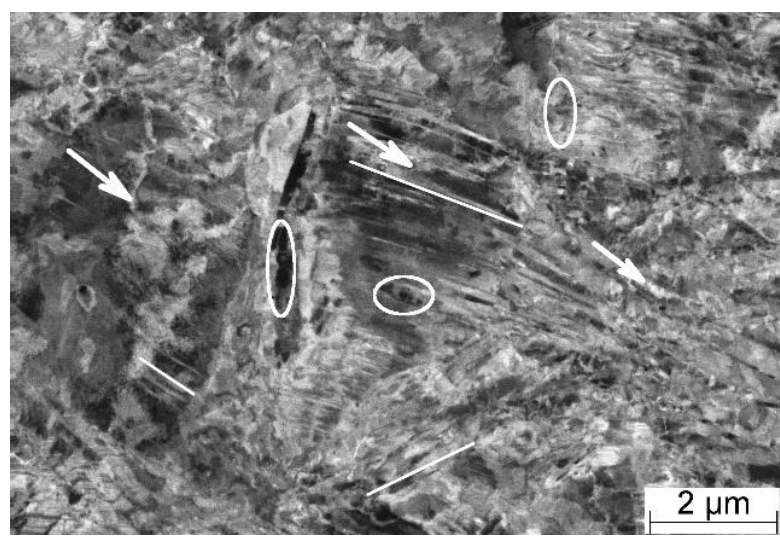

b) $16 \mathrm{Cr}-7 \mathrm{Mn}-6 \mathrm{Ni}$

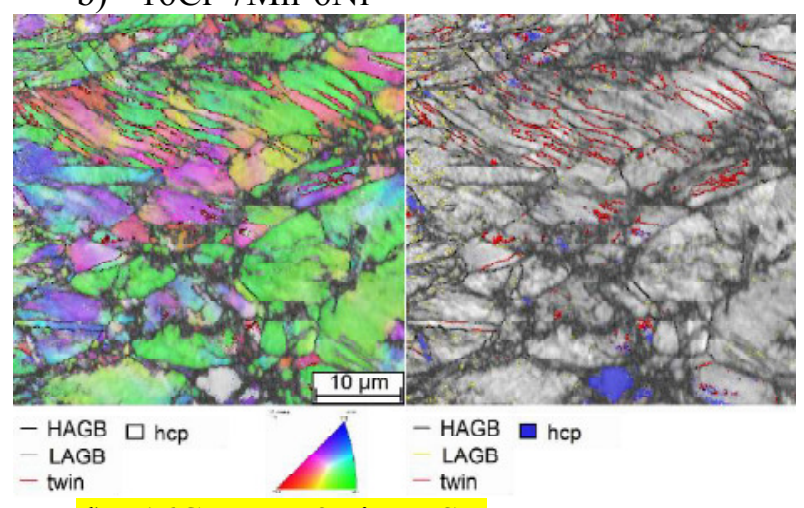

d) $16 \mathrm{Cr}-7 \mathrm{Mn}-9 \mathrm{Ni}, \mathrm{EBSD}$

Figure 7. ECCI micrographs (a-c) and EBSD map (d) of individual samples after the maximum deformation. a) Deformation bands (marked by straight lines), stacking faults (arrows) and $\alpha^{\prime}$-martensite (circles) in 16Cr-7Mn-3Ni. b) Extremely defect-rich microstructure of sample 16Cr-7Mn-6Ni with dislocations (arrows), dense deformation bands (lines) and $\alpha^{\prime}$-martensite (circles). c) Dislocation structures (arrows) and curved deformation bands (lines) identified as E-martensite and twins in 16Cr-7Mn-9Ni. d) EBSD maps of sample 16Cr-7Mn-9Ni, left: showing the grain orientation and grain boundaries, especially twins (red lines), as well as local occurrence of hcp \&-martensite (light grey). On the right mapping of the same area, the grain and twin boundaries are delineated together with the band contrast (grey). 


\section{Text for Table of Contents}

The deformation mechanisms in $16 \mathrm{Cr}-7 \mathrm{Mn}-x \mathrm{Ni}$ steels with different $\mathrm{Ni}$ contents $(3,6$ and 9 wt.\%) and thus with different stacking fault energies are investigated using in situ synchrotron radiation diffraction under uniaxial compression. The evolution of microstructure defect densities and martensitic phase transformation are tracked and their correlation and effect on the mechanical behavior are described.
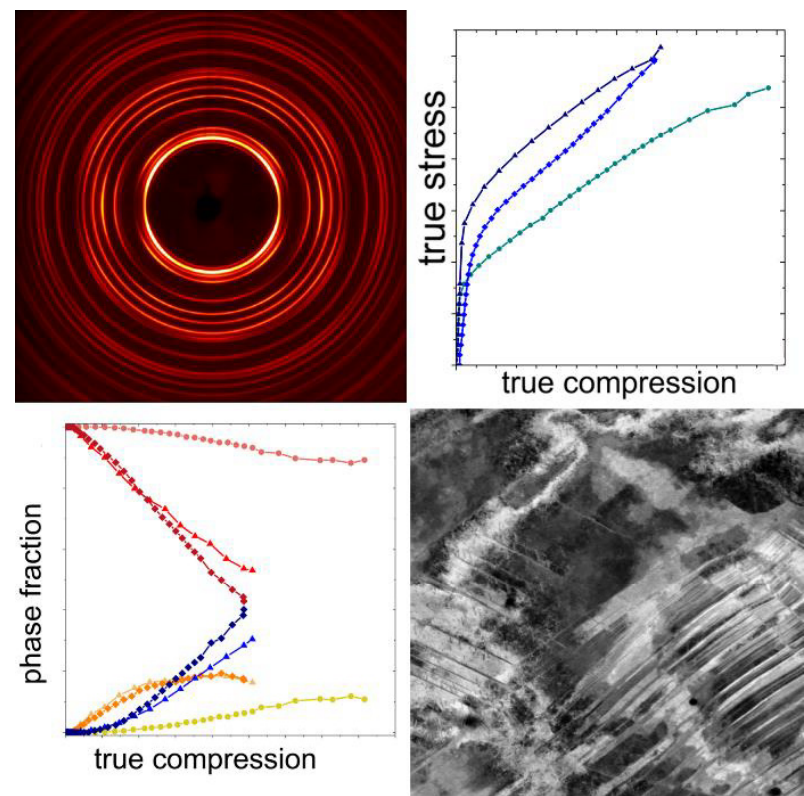